\title{
Sustainable Policymaking: Balancing Profitability \& Sustainable Development in Businesses
}

\author{
Nicolas Viens ${ }^{1}$, Denise Fortier ${ }^{1}$
}

\begin{abstract}
Despite multiple decades' worth of credible data confirming the extent of sustainability problems, our society has subsequently shown very limited progress with finding viable solutions on such critical subjects. Indeed, there is growing evidence of a general misunderstanding regarding the challenges related to the climate change issue. More specifically, we point to evidence outlining sustainable development (SD) and climate change as complex meta-problems. This explains why current global environmental policies are inefficient in addressing the causes of SD and climate change and why they fail to induce sustainable practices in consumers and organizations. In this paper, we argue that the primary obstacles businesses face in adopting proper sustainable practices are found in their neoclassical business worldview and in the increased competition levels resulting from internationalization and market deregulation. To counter these obstacles, we suggest solutions that have the potential to bring true SD. First, we believe the use of specific economic tools such as sovereign funds, green investments and ethical financial indexes, can have significant effects on neoclassical businesses in stewarding them towards sustainable practices. Finally, we call for increased interdisciplinary interactions between the scientific community, policymakers and business leaders in order to better manage meta-problems related to climate change.
\end{abstract}

Keywords: Sustainable development, policy, meta-problems, interdisciplinarity

\section{Introduction}

The development of several Earth monitoring programs in the second half of the $20^{\text {th }}$ century led to a paradigm shift regarding our understanding of environmental fluctuations across the globe as well as the realization that, due to natural resource exploitation, industrialization and increased world population, humankind has had a significant impact on the planet. The gathering of satellite data (e.g. land and water resources, atmosphere, cryosphere and biosphere) served to confirm the correlation between increasing atmospheric $\mathrm{CO}_{2}$ and global warming, and to highlight the potential issue of climate change (Baüer, Gérard, \& Minster, 2006). As such, data from NASA's Applied Sciences Program, the World Weather Watch (WWW), the Committee for Earth Observations Satellites (CEOS), and the Global Climate Observing System (GCOS) marked a strong shift in our understanding of human impact on the planet, finally proving humankind's responsibility for our planet (National Aeronautics and Space Administration [NASA], 2006). However, despite large quantities of data and international agreements like the 1997 Kyoto Protocol and the 2015 Paris Agreement, our society has subsequently shown very limited progress in sustainable development. Polluting rates like greenhouse gas emissions keep increasing, consequently reaching alarming levels (Hémous, 2016; Olivier, Shure, \& Peters, 2017). We can therefore 
conclude that environmental policies implemented by governments have proven ineffective in changing organizational practices around the world.

This paper seeks to shed light on this problem by answering the following question: In the face of years of data revealing the unsustainability of the global organizations, what has prevented policymakers from inducing the required changes? The purpose of this paper is thus twofold: It aims to 1) identify the general obstacles that limit the successful development and implementation of effective environmental policies on a macroscopic level, and 2) suggest more effective alternatives for policymakers to induce organizations to make required changes. A review of literature led to the identification of two main obstacles that limit the implementation of national or international sustainable development policies. First, growing evidence shows that the neoclassical perspective of corporations and its inherent short-term vision prevent firms from undertaking sustainable practices. Instead, we continue to observe an excessive focus placed only on the financial bottom line, at the expense of the social and ecological dimensions of the Triple Bottom Line. Second, increased competition between businesses due to market deregulation and internationalization limits the incentives and opportunities for firms to engage in environmentally responsible practices. Parallel to these obstacles, we believe that the leading actors in the development of sustainable policies fail to consider the issue of climate change as a meta-problem, which leads to significantly flawed strategic thinking. Such lack of understanding of the true complexity and interrelation of a substantial quantity of factors that can affect corporate action could explain the apparent ineffectiveness of the policies implemented.

Accordingly, we outline two solutions to the outlined challenges that should prove more effective in inducing change. Based on the continued predominant neoclassical organizations and the nature of market competition, along with an illustration of the complexity and interconnection of meta-problems linked to the climate change issue, we believe that economic tools can have significant impacts toward increasing sustainable development in large corporations. Moreover, emerging literature on the extent and severity of environmental changes strongly suggest the need for interdisciplinarity of academic programs and any decision-making group. Such collaboration between disciplines is believed to be a competence factor for solving meta-problems, as it should improve the dialogue between concerned parties, thus enhancing understanding of the complexity of sustainability. We believe the combination of these solutions is our best bet if we want organizations to become more sustainable and forward-looking.

\section{Part I: Obstacles}

\subsection{Defining the Neoclassical Worldview}

There are mainly two schools of thought regarding the optimal method in reaching a sustainable society. Sustainable development would come either from inducing changes in consumer behaviour that would eventually force companies to adapt their offerings, or by involving policymakers to work directly with organizations in order to develop sustainable products and business operations. This paper will focus on the latter option, as we believe it can have the most impact on society, notably given that the 
business-to-customer market is only a portion of the global economy; consumers thus have limited influence in certain markets and industries, and literally none in others. It is also believed that modern businesses rose to such size and power that they are now the only institutions that can properly foster changes favourable to develop a sustainable culture in businesses and society (Hawken, 1993).

Consequently, we believe that understanding the most dominant mindset within which businesses operate and whether it favours sustainable development is the first step in identifying obstacles to developing enduring practices. Working with the concept of worldview as "the constellations of beliefs, values and concepts that give shape and meaning to the world a person [or organization] experiences and acts within" (Norton, 1991, p.75), it is one that has been coined under different terminology. Gladwin, Kennelly \& Krause (1995) label this worldview as the "technocentric paradigm", while Stubbs \& Cocklin (2007) refer to it as the "neoclassical worldview", as a reference to this concept's deep roots in the neoclassical economic model. Indeed, an inherent characteristic of neoclassical economics is priority being placed on maximizing an organization's profits and financial performance (Stubbs \& Cocklin, 2007; Weintraub, 2002), ultimately disregarding natural resource depletion in the process. It is also the mentality Milton Friedman (1970) refers to when he claims that an organization's only goal should be to maximize shareholders returns. Currently the dominant paradigm today (Egri \& Pinfield, 1996), technocentrism treats humans as dissociated from- and above- the biosphere due to their superior intelligence (Gladwin et al., 1995). As such, technocentrism views the Earth as an inert entity legitimately exploitable, with nearly infinite supply of natural resources. In the case of an eventual natural resource shortage or exhaustion, humankind is believed to be capable of generating a perfect substitute through its intelligence and technology. This mindset has resulted in a strong reactive attitude towards environment degradation and ecological disasters.

In terms of organizational structure, the neoclassical approach creates typically highly hierarchical organizations, grounded in self-centered reasoning (Gladwin et al., 1995). They are also renowned for their short-term focus in financial performance as well as planning cycles, where quarterly returns are privileged (Costanza et al., 1991). Neoclassical organizations seek cost reduction, market share expansion and tend to be highly competitive in the process (Stubbs \& Cocklin, 2007). Moreover, employees are usually perceived as "costs" that must be reduced or optimized; social welfare must also be limited as it tends to fall under the responsibility of the government. Clearly, this worldview is not conducive to be investing in the triple bottom line. However, we side with Steurer et al. (2005) when they point out that some social or ecological policies can be adopted by a firm if it believes such action will lead to greater returns.

Finally, no worldview is inherently wrong (Gladwin et al., 1995). Analyzing different worldviews should not be meant to blame specific organizations for unsustainable practices. In fact, the neoclassical worldview allowed for the construction of our current economic model along with the great technological advances that resulted from industrialization since the $19^{\text {th }}$ century. However, now that our society has grown in size and reached a high level of technology, the manner in which organizations operate within this worldview and exploit capital has truly become unsustainable. As population grew, so did its demand for resources and energy. As such, the neoclassical approach 
became an issue only when the very rate at which we depleted resources exceeded the rate at which resources were produced (Benyus, 2002; Wielkiewicz \& Stelzner, 2005). We agree that it is not necessarily productive to debate whether a worldview is right or wrong. Instead, we explore a worldview's potential for sustainability based on predetermined criteria and on the needs of society. Based on this premise, we conclude that organizations working with a neoclassical worldview, through their limiting mindset and vision, have become an obstacle to sustainable development.

\subsection{Increasing Competition}

Increasing intensity of competition in given markets, due to globalization and deregulation, can explain why neoclassical organizations have a bare-bones approach to costs and benefits. By emphasizing offshoring and outsourcing activities, globalization results in significant trade-offs to organizations as it can increase cost-based competition, limit differentiation and affect value chains (Delios, 2010). In turn, we observe an increase in the dependence of suppliers, limiting their bargaining power to fewer, large buyers. Notwithstanding the fact that highly competitive markets can lead to unethical behaviour (lobbying, control of suppliers, increasing prices or barriers of entry), there is growing evidence that such rivalry can be highly detrimental to the long-term well-being and prosperity of organizations across markets (Delios, 2010; Luo, 2007).

Although monopolistic markets can also be dangerous and dilute both the purchasing power of consumers and suppliers' bargaining power, there are several cases where, in the face of a limited number of competitors, organizations could afford to be more munificient in terms of social responsibility (Delios, 2010). However, in situations where the market would eventually become internationalized and deregulated, the benevolent firm would have no other choice but to cut back on its costs and offered benefits in order to remain competitive. Although we argue that organizations are more than simply transactional entities and should bring social benefits, we accept that they also have to be financially viable. In Delios's (2010) words, "it is challenging to care when the organization no longer exists" (p. 30). Thus, the key for sustainable initiatives to be carried out by competitive organizations lies in the benefits such organizations stand to gain by being socially responsible and to generate a comparative advantage from social responsibility, sustainable initiatives or innovation (Delios, 2010; Gladwin et al., 1995).

\subsection{Wicked Complexity: The Challenge Behind Meta-Problems}

Any policy developed unilaterally by a body or agency will be prone to mere problem displacement and problem shifting, which represent the core of reductionist measures, where lack of understanding of the complexity of the issue is usually the source of the problem. Attempts to solve small portions of the problem are done without realizing the interrelation of all components, thereby leading to ineffective measures and minimal improvements (Baumgartner \& Korhonen, 2010). The apparent failure of current environment policies thus suggests that issues related to climate change and sustainable development are specifically meta-problems (Allenby, 2011; Chevalier, Bailey, \& Burns, 1974; Roome, 2001). Simply put, a meta-problem is a complex problem constructed of other complex problems (Baumgartner \& Korhonen, 2010; Roome, 2001). The complexity of a meta-problem lies mostly in the interconnection of each 
component or sub-problem that consists it. Consequently, any attempt to solve parts of a meta-problem will result in influencing and altering other subsets of this interwoven system (Roome, 2001). Solutions are then extremely difficult to conceptualize, process and implement.

There are mainly two reasons why meta-problems are so difficult to manage. First, since such systems are constantly evolving and expanding in several, distinct ways, it is believed that these issues cannot be purely solved, but instead can only be managed (Allenby, 2009). The second difficulty inherent to meta-problems comes from human perception biases. Indeed, due to the multiple characteristics inherent in a meta-problem, organizations will usually only be affected by limited parts of the entire issue and therefore focus only on the elements that affect them (Roome, 2001). Consequently, the perceived relevance of initiatives to undertake, along with the desired results, will vary substantially. Since the management of a meta-problem tends to be done in silos rather than in a coherent whole, it increases ambiguity and subjectivity over the management of such problems and further reduces the effectiveness of resulting policies, or extends the time to actually act on the problem (Roome, 2001).

To be truly sustainable, policymakers must first acknowledge the complexity of the issue at hand as a whole, notably through strategic thinking. Reductionism can then be limited while more effective and sustainable solutions are implemented. This element comes directly in opposition with the neoclassical ideology's optimistic view of the future, believing that humankind can overcome any natural disaster or emerging shortage from its capacity for ingenuity and technology (Gladwin et al., 1995). Evidence shows that the failure to solve meta-problems does not lie in a lack of technological innovation or our capacity to implement drastic or disruptive changes, but in our inability to implement farreaching and long-term changes (Chevalier et al., 1974). Hence, ingenuity does not matter if we do not have the capacity to properly manage and implement the results from developed technology and innovation. Solutions that grasp the entire complexity of meta-problems must be implemented to successfully create a sustainable society.

\section{Part II: Solutions}

Given the extent of arguments confirming the unsustainable nature of the neoclassical mindset, one could assume that such a flawed worldview should be replaced by a more holistic business mindset. While this option might be optimal, it would be extremely difficult to be carried out, and would call for a very lengthy process. Indeed, given the general acceptance of this mindset across the world, any attempt to change it would result in severe resistance to change. As such, this option is not very viable if we are to generate proper sustainable development in a reasonable time frame, especially considering the growing urgency of inducing sustainable changes soon.

Additionally, the fact that neoclassical organizations are usually heavily structured, hardened by sunk costs, partnerships with other organizations and grounded in a strong need for accountability and reliability, results in strong inertia against radical change (Wielkiewicz \& Stelzner, 2005). Even if the neoclassical worldview would come to be replaced with a more sustainable approach, we believe that it would take an excessive amount of time before it is successfully completed. Alternatively, policymakers could 
instead use the dominant neoclassical worldview to their advantage in moving organizations through compliance towards sustainability in a more immediate manner. Once such policies are in effect, working to slowly transform the neoclassical mindset can be considered, resulting in organizations internalizing over time sustainability practices within their own mindset. As such, we argue for the solutions outlined below with the first emphasizing short-term results and the second seeking long-term changes in the way businesses operate.

\subsection{Economic Tools}

The key element for policies to be effective on a global scale is to target organizations uniformly. To that extent, the growing interconnection of meta-problems to various dimensions of our world can also be turned to policymakers' advantage. Indeed, economic, financial and trade systems have become greatly interconnected with every nation's economy (Roome, 2001), which creates a fertile field for developing uniform policies and affect as many organizations as possible. Hence, given that neoclassical organizations are single-focused on their financial welfare, the first and more immediate solution in tackling the sustainability issues would be to use economic and financial tools, namely sovereign funds, green investments and ethical financial indexes to steer neoclassical organizations toward sustainable practices.

The way we measure a nation's economy can incentivize policymakers and organizations in seeking to maximize results based on the specific metrics being used, while disregarding elements that are not being considered in the measure. This is in fact the critic thrown by several economists at the use of the gross domestic product (GDP) as an economic measure since, out of its various intricate flaws, it fails to subtract the costs of growth and the depreciation of the capital used in production (Goodstein \& Polasky, 2014). Nevertheless, the GDP has still become the most popular and universal indicator of economic growth (Talberth, Cobb \& Slattery, 2006). It is thus to prevent false sense of economic progress that various groups of experts developed other metrics- like the net national welfare (NNW) or the genuine progress indicator (GPI). Although these indicators can vary from one another regarding the variables measured, they are nonetheless based on the same initial premise; using a proper measure of economic growth that deducts costs associated with the exploitation of natural capital would ensure that increased current welfare is not incurred at the expense of future generations (Goodstein \& Polasky, 2014; Talberth et al., 2006).

In other words, for a natural resource to be exploited in a sustainable way, the rents from its exploitation should be properly invested so that future generations still benefit from this resource. If the resource rents are simply consumed instead of being reinvested, the natural resource depletion is then unsustainable (Goodstein \& Polasky, 2014). It is then based on that extent that a large part of sovereign funds- a financial fund owned and controlled by a state that holds parts of the state's national savings- have been created (Junghans, 2008). As such, we argue that such sovereign funds can have a significant impact in directing organizations toward sustainable development, notably for their longterm perspective in investments, their increase in size and influence since the middle of the 2000's and for giving back power to states through a change in their strategic use (Coeuré, 2009; Junghans, 2008; Karyotis, 2011). 
While an organization seeks to bring returns to its shareholders as fast as possible, a country usually focuses on very long-term survival and growth, and thus will base its decisions in order to reach this goal. Consequently, when a state invests parts of its national savings, it will normally do so with the same long-term perspective as with its fiscal policies. This element has thus become increasingly significant since the beginning of the $21^{\text {st }}$ century, as the size and quantity of sovereign funds skyrocketed, from only three of such funds existing in 1969 to 56 in 2009, and expected to hold over $10 \%$ of the global economy by 2020 (Karyotis, 2011). Additionally, the strategic use of sovereign funds also changed drastically. Before 2005, most of these funds capitalized in safe investments, providing small but risk-free returns. Since then, a great portion of sovereign funds are used more aggressively, investing in high-risk, high-return investments and even for ownership of companies (Junghans, 2008). This has led to a rise in power of states over the decisions of organizations (Karyotis, 2011). Consequently, Coeuré (2009) explains that a state shareholder behaves differently than a neoclassical organization; it will not simply aim at maximizing value, but will also consider other dimensions such as the common interest of its population, technology transfers or resource sovereignty.

Green investments have also gained size and influence since the 2000's. They are notably becoming more popular among the Millennials generation, growingly more conscious about where and how their savings are being invested (The Economist, 2017). Hence, sustainable and responsible investments have drastically increased over the years (Global Sustainable Investment Alliance [GSIA], 2016). As such, growingly conscious individuals as well as private funds can also have the potential of influencing organizations in further investing in green technology or socially responsible practices (Gao \& Zheng, 2017). For instance, in January 2018, financial markets were shaken by the change in direction of the investment firm BlackRock, one of the most influential investing firms in the world, managing over US\$6 trillion in investments, as it alerted all its partnered businesses that organizations will now need to contribute to society, or risk losing BlackRock's financial support.

It is the first time that such an investment firm with such size and influence over so many organizations stands up and aims at increasing the social contribution of organizations. Added with the growing influence of sovereign funds, these financial tools are putting uniform pressures on economic markets in which organizations are thus effectively affected. It is precisely for the non-unilateral aspect of these types of investments that we believe these financial tools can have a significant effect on organizations in adopting more sustainable practices.

While the rise of sovereign funds and green investments have increased the number of incentives for organizations to become socially responsible, the increased globalization of markets and the relative subjectivity in being socially responsible can make it difficult for shareholders to acknowledge the truly responsible organizations from other, less caring ones (Consolandi, Jaiswal-Dale, Poggiani \& Verceilli, 2008; McWilliams \& Siegel, 2011). As such, the use of financial indexes that can rate organizations either in terms of their CSR standing- like the Dow Jones sustainability stoxx index (DJSSI), their ethical behaviour or sustainable practices can help shareholders invest properly and further increase the incentives an organization would have in being socially or ecologically 
responsible.

Indeed, ethical indexes not only increase pressures on organizations to become sustainable, but can also create a sense of coveted position to organizations granted a rank in these indexes, the same way obtaining a certification can improve an organization's standing over its competitors (Consolandi et al., 2008). While there are yet only few of such indexes, evidence suggest they have a growing potential to have a significant impact on global financial markets and thus influencing organizations in adopting true sustainable practices, as it is growingly becoming in their financial interest to do so (Consolandi et al., 2008; McWilliams \& Siegel, 2011).

\subsection{Interdisciplinarity}

While financial tools have the potential of allowing organizations to generate a comparative advantage and financial returns through sustainable initiatives, attempts should still be made to change the mostly unsustainable nature of the neoclassical worldview. Consequently, for organizations to consider more than their financial welfare, those who manage organizations should first be trained to create value in a more holistic way. As such, it is believed that universities should turn to interdisciplinary research and teaching curricula so they may offer courses to broaden the perspectives of students and enable them to better integrate sustainability considerations in their professional practices (Stubbs \& Cocklin, 2007).

Interdisciplinarity is relevant in academic programs; higher education institutions can play an important role in shaping young students into sustainability actors, encouraging them to subsequently prioritize such considerations into the workplace. Studies show that academic organizations can be effective communication channels through the educational and formative experience they provide to a high number of young individuals, most being at a stage of personal identification and adopting lasting values (Lertpratchaya et al., 2017). Academic institutions should then make significant efforts in implementing sustainable practices both in their education programs and on their campuses. Even though such initiatives would take some time before resulting in visible change, a dialogue about the reform of business and MBA programs should be nonetheless initiated promptly across academic institutions.

Additionally, interdisciplinarity appears to be a determining factor in successfully managing meta-problems and developing resulting policies that have the potential for significant, long-term benefits, thus avoiding reductionism and problem shifting (Allenby, 2011; Chevalier et al., 1974; Baumgartner \& Korhonen, 2010; Roome, 2001). As such, any decision-making group, policymaker, executive board, government, thinktank or agency, can benefit from increasing its professional interdisciplinarity when facing meta-problems, or at least engage in interdisciplinary information exchanges with other organizations (Benyus, 1995; Roome, 2001).

Interdisciplinarity implies the construction of a heavily diversified decision-making group with members having very different professions or experience and appears to be effective in managing meta-problems for a few key reasons. First, the interaction of heterogeneous individuals allows for a greater breadth of knowledge at the disposal of the decision-making group, resulting in more effective decision-making (Chevalier et al., 1974). Also, while group-decision processes are rather advantageous for any 
organization, as it increases the number of feedback loops, the effectiveness of the group is strongly related to its diversity (Wielkiewicz \& Stelzner, 2005). The separation between social fields from scientific and engineering disciplines has thus proven to be a catalyst of reductionism and problem shifting (Baumgartner \& Korhonen, 2010). Although specialization remains highly important in several fields and professions, benefits are not optimal when there is minimal interaction between disparate fields.

Interdisciplinarity can thus be an effective counterbalance to individuals blinkered by professional specialization, which limits their capacity to solve multi-faceted problems. It can in fact optimize the collective competence of experts working together (Benyus, 2002). For instance, the emergence of biomimicry, the imitation of natural elements for engineering applications, shows how engineers can benefit from interacting with biology experts, and vice-versa. Additionally, while scientific experts hold the knowledge and information about the planet's state and the resulting urgency in adopting more sustainable practices, they are not well equipped to either forward the information to the masses successfully, or produce effective social policies (Allenby, 2011). Indeed, as Allenby (2011) has stated, "if you want to include politics, regulation, and communication in your consideration of a complex issue, you need to get experts in those fields" (p.120). In all, we believe interdisciplinary interaction is a key element to be implemented in any policymaking group when faced with heavily complex problems.

In conclusion, we aimed throughout this text to shed light onto various components that appear to be obstacles for organizations in becoming more sustainable. We argue that it is imperative to first have a general understanding of these components before attempting to develop policies affecting organizations or industries. The various obstacles outlined have painted a very intricate picture, whereas attempting to grasp it entirely can be quite overwhelming. As Allenby (2011) puts it; "how can such disparate disciplines and, indeed, worldviews, be brought together in ways that facilitate more sophisticated understanding of the complex adaptive systems that sustainability science necessarily engages?" (p.120). With the solutions proposed through the growing understanding of these obstacles, we are confident that policymakers can succeed in steering organizations successfully on the path of sustainability within a viable timeframe.

\section{References}

Allenby, B. (2011). Thoughts on Industrial Ecology, Emerging Technologies, and Sustainability Science. Integrated Research System for Sustainability Science, Vol. 6, p.119-122.

Allenby, B. (2009). The Industrial Ecology of Emerging Technologies. Journal of Industrial Ecology, Vol. 13(2), p.168-183.

Baüer, P., Gérard, F., \& Minster, J.-F. (2006). Observing the Earth: An international endeavour. Académie de Sciences, Paris.

Baumgartner, R.J., \& Korhonen, J. (2010). Strategic Thinking for Sustainable Development. Sustainable Development 18(2), p.71-75.

Benyus, J.M. (2002). Biomimicry: Innovation Inspired by Nature. New York, NY: Morrow.

Chevalier, M., Bailey, L., \& Burns, T. (1974). Toward a Framework for Large-Scale Problem Management. Human Relations, Vol. 27(1), p.43-69.

Coeuré, B. (2009). Faut-il avoir peur des fonds souverains? Cahier du Cercle des économistes, p.85-97.

Consolandi, C., Jaiswal-Dale, A., Poggiani, E., \& Vercelli, A. (2008). Global Standards and Ethical Stock Indexes: The Case of the Dow Jones Sustainability Stoxx Index. Journal of Business Ethics, 87, p.185-197. 
Costanza, R., Daly, H.E., \& Bartholomew, J.A. (1991). Goals, agenda, and policy recommendations for ecological economics. Ecological Economics: The Science of Management of Sustainability, Columbia University Press, New York.

Delios, A. (2010). How Can Organizations Be Competitive but Dare to Care? Academy of Management Perspectives, Vol. 24(3), p.25-36.

Egri, C.P., \& Pinfield, L.T. (1996). Organizations and the Biosphere: Ecologies and Environments. Handbook of Organization Studies, Sage Publications, London.

Friedman, M. (1970). Social Responsibility of Business is to Increase its Profits. New York Times Magazine.

Gao, X., \& Zheng, H. (2017). Environmental Concerns, Environmental Policy and Green Investment. International Journal of Environmental Research and Public Health, Vol. 14.

Gladwin, T.N., Kennelly, J.J., Krause, T.-S. (1995). Shifting Paradigms for Sustainable Development: Implications for Management Theory. The Academy of Management, Vol. 20(4), p.874-907.

Global Sustainable Investment Alliance (2016). 2016 Global Sustainable Investment Review.

Goodstein, E.S., \& Polasky, S. (2014). Economics and the Environment. Seventh Edition.

Hawken, P. (1993). The Ecology of Commerce: A Declaration of Sustainability. New York.

Hémous, D. (2016). The Dynamic Impact of Unilateral Environmental Policies. University of Zürich, Switzerland, Journal of International Economics, Vol. 103, p.80-95.

Junghans, P. (2008). Les fonds souverains, agents d'une vision patrimoniale de la mondialisation. Géoéconomie, Vol. 4(47), p.51-68.

Karyotis, C. (2011). Les fonds souverains, accélérateurs de la mutation du capitalisme mondial? Géoéconomie, p.131-150.

Lertpratchya, A.P., Besley, J.C., Zwickle, A., Takahashi, B., \& Whitley, C.T. (2017). Assessing the Role of College as a Sustainability Communication Channel. International Journal of Sustainability in Higher Education.

Luo, Y. (2007). A Coopetition Perspective of Global Competition. Journal of World Business, Vol. 42, p.129-144.

McWilliams, A., \& Siegel, D.S. (2011). Creating and Capturing Value: Strategic Corporate Social Responsibility, Resource-Based Theory, and Sustainable Comparative Advantage. Journal of Management, Vol. 42(5), p.1480-1495.

National Aeronautics and Space Administration (2006). Applications of Earth Observations for Societal Benefit: Results of Project Grants Beginning in 2006. NASA Earth Science, Applied Sciences Program.

Norton, B.G. (1991). Toward Unity Among Environmentalists. Oxford University Press.

Olivier, J.G.J., Shure, K.M., \& Peters, J.A.H.W. (2017). Trends in Global CO2 and Total Greenhouse Gas Emissions: Summary of the 2017 Report. PBL Netherlands Environmental Assessment Agency.

Roome, N. (2001). Conceptualizing and Studying the Contribution of Networks in Environmental Management and Sustainable Development. Business Strategy and the Environment, Vol. 10, p.69-76

Shrivastava, P. (1995). The Role of Corporations in Achieving Ecological Sustainability. Academy of Management Review, Vol. 20(4), p.936-960.

Steurer, R., Langer, M.E., Konrad, A., \& Martinuzzi, A. (2005). Corporations, stakeholders and sustainable development I: a theoretical exploration of business-society relations". Journal of Business Ethics, 61, p.263-281.

Stubbs, W., \& Cocklin, C. (2007). Teaching Sustainability to Business Students: Shifting Mindsets. International Journal of Sustainability in Higher Education (IJSHE), Vol. 9(3), p.206-221.

Talberth, J., Cobb, C., Slattery, N. (2006). The Genuine Progress Indicator: Executive Summary. Redefining Progress.

Unnamed Author (2017). Generation SRI: Sustainable Investment Joins the Mainstream. The Economist, retrieved from: https://www.economist.com/finance-and-economics/2018/05/12/barriers-to-entry

Weintraub, E.R. (2002). Neoclassical Economics. The Library of Economics and Liberty, retrieved from: http://www.econlib.org/library/Enc1/NeoclassicalEconomics.html

Wielkiewicz, R.M., \& Stelzner, S.P. (2005). An Ecological Perspective on Leadership Theory, Research, and Practice. Review of General Psychology, Vol. 9(4), p.326-341. 